\title{
Prescription Pattern of Antituberculosis Drugs in Treatment of Tuberculosis at a Tertiary Care Hospital in Andhra Pradesh, a Cross-Sectional Study
}

Krishnakanth $\mathrm{K}^{1}$, Chakrapani Cheekavolu²*, Pojala Kumar³, Ravi Shankar K ${ }^{4}$, Jagadeesh A

${ }^{1}$ Department of Pharmacology, NRI Medical College and Hospital, Chinakakani, Guntur-522503, Andhrapradesh, India.

${ }^{2}$ Department of Pharmacology, Karpagam Faculty of Medical Sciences and Research,

Othakkalmandapam, Coimbatore - 641 032, Tamil Nadu, India

${ }^{3}$ Department of Pharmacology Dr Pinnamaneni Siddhartha Institute of Medical Sciences

Chinaoutpalli, Krishna- 521286, Andrapradesh, India

${ }^{4}$ Department of Pharmacology, NRI Medical College and Hospital, Chinakakani, Guntur-522503, Andhrapradesh, India

${ }^{5}$ Department of Pharmacology, NRI Medical College and Hospital,

Chinakakani, Guntur-522503, Andhrapradesh, India

The success of tuberculosis treatment is based upon the prescription pattern following Revised National Tuberculosis Control Programme/National Tuberculosis Elimination Program/World Health Organization guidelines, reflecting the burden of the disease which is increasing yearly. This implicates the variations in prescriptions advised in the treatment of tuberculosis. The present study was aimed to evaluate the prescription patterns of tuberculosis treatment in a tertiary hospital at Andhra Pradesh, India. Ninety-two patients were included in the study after obtaining ethical approval and informed consent. The prescription patterns were evaluated and compared to the standard guidelines. The mean age of the patients was 38.72 and showed male preponderance. Six regimens were used during the treatment. The patients showed good recovery which concludes that following the standard prescription pattern provides a good success rate in the treatment of tuberculosis.

Keywords: Anti-tuberculosis therapy; observational study, treatment regimens

\section{Introduction}

Tuberculosis in human is principally caused by Mycobacterium tuberculosis and it is a worldwide pandemic. Though newer modalities and treatments have evolved, still millions are being affected by this disease. ${ }^{1}$

National Tuberculosis Elimination Program (NTEP) 2020 was introduced by the government of India with an aim to cut the disease transmission chain and end tuberculosis (TB) disease in India by $2025 .^{2}$ In spite of diagnostic and treatment advancements, unfortunately, a large population is still affected from TB. Deaths due to TB were 2 million during 2013 and it has increased further during 2019. ${ }^{2}$

Adverse drug reactions (ADR) are a great burden to national anti-tuberculosis program.

Corresponding author: Dr Chakrapani Cheekavolu. Associate Professor, Department of Pharmacology. Karpagam Faculty of Medical Sciences and Research, Othakkalmandapam, Coimbatore. Tamil Nadu, India. Email: chakri14783@gmail.com Received: 24 August 2020. Revised: 8 September 2020. Published: 1 October 2020. 
The prescription pattern can affect the compliance of treatment negatively, which results in MDR-TB indirectly., ${ }^{4,5}$ With this background, the present study was initiated to evaluate the prescription pattern in tuberculosis treatment.

\section{Methods}

This prospective cross-sectional, observational study was conducted in the pharmacology department and pulmonary medicine out-patient department at NRI Medical College and General Hospital, Andhra Pradesh. This study was conducted during January 2020 to July 2020 for a period of six months. All new cases prescribed for the treatment of tuberculosis were enrolled in the study after obtaining the institutional ethics approval (IEC NRIMC 128 dated 25 January 2020) and informed consent from the patient. Total of 92 patients were included in the study. The patients with age range of 1580 years of either sex with active or inactive TB were included in the study. Patients not willing to participate or to provide consent were excluded from the study.

The prescriptions were obtained from the patients and the data was documented. The obtained data was compared with the standard Revised National Tuberculosis Control Programme (RNTCP)/NTEP 2020 guidelines of India. The sample size included all the new patients of tuberculosis treatment during the study period, willing to participate in the study as per inclusion criteria.

The prescriptions were also evaluated as per the recent WHO guidelines. The prescription was stated as correct if it includes the following criteria like at least 4 first-line anti TB drugs were prescribed, all doses adjusted as per weight, all patients were advised to take the daily dose of drugs at once or at the same time, no second-line drug since drug- resistant TB patients were not included in the study. ${ }^{6}$

\section{Statistical Analysis}

Statistical analysis was done using GraphPad Prism online software. In the current study the data was expressed in $\mathrm{n}(\%)$, mean and standard deviation (SD).

\section{Results and Discussion}

One-fifth of global TB cases are accounted from India. ${ }^{6}$ The Revised National TB Control Programme (RNTCP) which is directly observed treatment, short-course (DOTS) based has achieved a remarkable success rate of $85 \%$ cure. ${ }^{7,8}$ This prospective observational cross-sectional study included 92 patients out of 100 screened patients. Eight patients were excluded from the study as they were not willing to participate in the study.

The prescription patterns were observed and documented. The mean age of the patients was 38.72 years and the baseline mean BMI was $21.32 \mathrm{~kg} / \mathrm{m}^{2}$. The mean age is comparable with the previous study in India ${ }^{9,10}$ and similar BMI category was observed majorly in other studies. ${ }^{11,12}$ All the patients were smearpositive in pulmonary type or confirmed as positive TB of extra-pulmonary type and category I (no history of antituberculosis drug therapy). All the patients included in the study had completed follow-up for six months and with no dropouts.

The encounters were compared and analyzed with respect to prescription patterns and standard treatment following the RNTCP guidelines. Totally 276 encounters were analyzed for prescription pattern which included first visit and 2 follow-up visits of ninety-two patients after confirmed diagnosis. The demographic details of the patients were tabulated in Table 1. Male preponderance 
was observed among the patients of this study, however the study sample was small to define the level of incidence. This preponderance was also reported by Rao S (2009). ${ }^{13}$ The patients were of category I defined as per RNTCP guidelines, including both pulmonary TB and extra-pulmonary TB cases. Among 92 patients, 3 female cases presented with extra-pulmonary TB.

The percentage of each drug type prescribed was depicted in Figure 1. The prognosis of patients did not necessitate the use of secondline drugs or injectables. The analysis of prescribed regimens suggested that the RNTCP guidelines 2018 were followed for the treatment of tuberculosis in all the patients. Total of 1246 drugs were prescribed in 276 encounters. The average number of drugs prescribed per encounter during the initiation of therapy was $6.85 \pm 0.34$. The average number of drugs prescribed per encounter during the first follow-up visit was $5.86 \pm 0.34$.

The total number of regimens used was 6 (Table 2). Adjuvant treatment with Pyridoxine 10mg OD, Pantoprazole 40mg OD, Domperidone 10mg/Ondansetron $4 \mathrm{mg}$ OD was suggested to patients based on symptoms like polyneuropathy, abdominal pain or heart-burn, and nausea or vomiting respectively. ${ }^{14-16}$ The total number of doses of drugs prescribed to the patients during the entire course of treatment was 1246.

All the prescriptions evaluated in the study adhered to the guidelines. Due to the small sample size, the recovery rate did not correlate with that of previous studies showing up to $85 \%$ of recovery following the guidelines. ${ }^{17,18}$ This may be a limitation to the study.

Table 1: Patient Characteristics

\begin{tabular}{lccc}
\hline No & Patient & & $\begin{array}{c}\text { Mean } \pm \text { SD } \\
(\mathrm{n}=92)\end{array}$ \\
\hline 1 & Characteristics & Male & 77 \\
& Gender $(\mathrm{N})$ & Female & 15 \\
2 & Age $($ Years $)$ & & $38.72 \pm 11.6$ \\
3 & BMI $\left(\mathrm{kg} / \mathrm{m}^{2}\right)$ & & $21.32 \pm 1.8$ \\
4 & Site of Disease (N) & Pulmonary & 89 \\
& & Extra Pulmonary & 3 \\
\hline
\end{tabular}

$\mathrm{n}=$ number of patients

Table 2. Regimens Used in the Study

\begin{tabular}{lccc}
\hline No & Regimen & $\mathrm{N}$ & $\mathrm{N} \%$ \\
\hline 1 & FDC-Isoniazid/Rifampicin/ Pyrazinamide/Ethambutol & 52 & 56.2 \\
2 & FDC- Isoniazid/Rifampicin/ Ethambutol & 52 & 56.2 \\
3 & Isoniazid, Rifampicin, Pyrazinamide, Ethambutol & 35 & 38 \\
4 & Isoniazid, Rifampicin, Ethambutol & 35 & 38 \\
5 & FDC- Isoniazid/pyridoxine, Rifampicin, & 5 & 5.43 \\
& Pyrazinamide, Ethambutol & & \\
6 & FDC- Isoniazid/pyridoxine, Rifampicin, Ethambutol & 5 & 5.43 \\
\hline
\end{tabular}




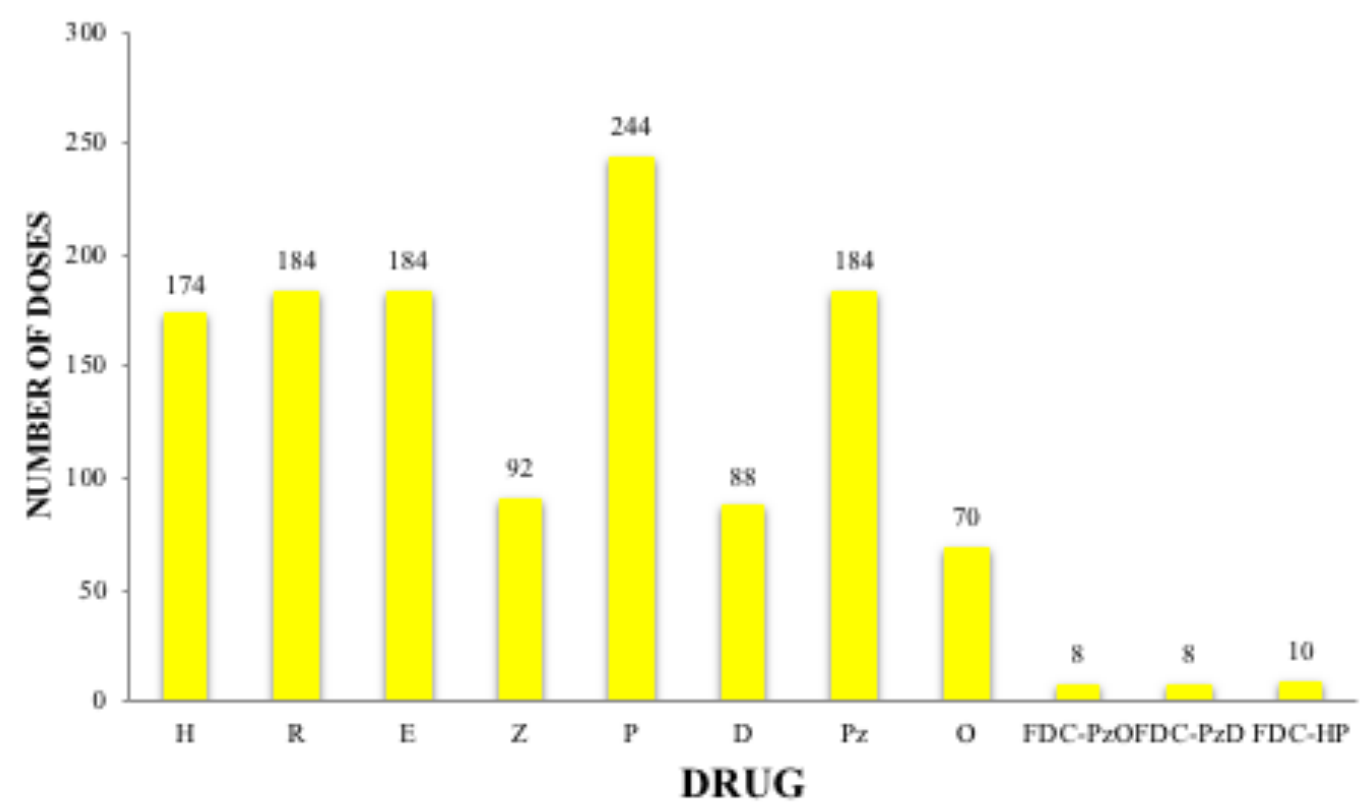

Figure 1. Drug dose frequencies used in the treatment of Tuberculosis. H-isoniazid, R-rifampicin, E-ethambutol, Z-pyrazinamide, P-pyridoxine, D-domperidone, Pzpantaprazole, $\mathrm{O}$ - ondansetron, FDC- fixed dose combination

\section{Conclusion}

Though the study includes ninety-two patients, no requirement of further prescription with anti-tuberculosis drugs after 6 months suggests that following the standard prescription patterns and guidelines provided complete success rate in the treatment of tuberculosis.

\section{Acknowledgement}

None

\section{Funding}

Nil

\section{Conflict of Interest}

None declared

\section{References}

1. Sandhu GK. Tuberculosis: current situation, challenges and overview of its control programs in India. Journal of Global Infectious Diseases. 2011;3(2):14350 .
2. Central TB Division, Ministry of Health \& Family Welfare, Government of India. TRAINING MODULES (1-4) FOR PROGRAMME MNAGERS AND MEDICAL OFFICERS. Central TB Division, Ministry of Health \& Family Welfare, Government of India. June 2020.

3. World Health Organization. Fact sheet no. 104: tuberculosis. Geneva: WHO. 2010.

4. Qayyum S, Ahmed I, Baig S, Rizvi $\mathrm{N}$. Adverse events in the treatment of multi-drug resistant tuberculosis. ERS. 2011;4402

5. Kurniawati F, Sulaiman SAS, Gillani SW. Adverse Drug Reactions of Primary Antituberculosis Drugs Among Tuberculosis Patients treated in Chest Clinic. Inetrnational Journal of Pharmaceutical and Life Sciences. 2012;3(1):13312-18.

6. World Health Organization, Stop TB Initiative (World Health Organization). Treatment of tuberculosis: guidelines. 
World Health Organization; 2010.

7. Dye C, Scheele S, Pathania V, Raviglione MC. Global burden of tuberculosis: estimated incidence, prevalence, and mortality by country. The Journal of the American Medical Association. 1999;282(7):677-86.

8. Murray CJ.Epidemiology and demography of tuberculosis. Adult Mortality in Latin America. 1996:199-216.

9. Udwadia, Z. F., \& Moharil, G. Multidrugresistant-tuberculosis treatment in the Indian private sector: Results from a tertiary referral private hospital in Mumbai. Lung India: official organ of Indian Chest Society. 2014;31(4):336-341.

10. Balvir Singh, Rajesh Kumar. Prescription Pattern of Second Line Antitubercular Drugs Prescribed by Private Practitioners: an Observational Study. International Journal of Scientific Research. 2016;5(9).

11. Zhang H, Li X, Xin H, Hengjing Li, Mufei $\mathrm{Li}$, Wei Lu et al. Association of Body Mass Index with the Tuberculosis Infection: a Population-based Study among 17796 Adults in Rural China. Science Reports. 2017;7:41933.

12. Bhargava A, Chatterjee M, Jain Y, Chatterjee B, Kataria A, Bhargava M et al. Nutritional status of adult patients with pulmonary tuberculosis in rural central India and its association with mortality. PloS one. 2013;8(10):e77979.

13. Rao S. Tuberculosis and patient gender: An analysis and its implications in tuberculosis control. Lung India : official organ of Indian Chest Society. 2009;26(2):46-47.

14. van der Watt JJ, Harrison TB, Benatar M, Heckmann JM. Polyneuropathy, anti-tuberculosis treatment and the role of pyridoxine in the HIV/AIDS era: a systematic review. International Journal of Tuberculosis Lung Diseases. 2011;15(6):722-8.

15. Hsu WH, Kuo CH, Wang SS, Lu CY, Liu
CJ, Chuah SK, et al. Acid suppressive agents and risk of Mycobacterium tuberculosis: case-control study. $B M C$ Gastroenterology. 2014;14:91.

16. Yang TW, Park HO, Jang HN, Yang JH, Kim SH, Moon SH, et al. Side effects associated with the treatment of multidrugresistant tuberculosis at a tuberculosis referral hospital in South Korea: A retrospective study. Medicine (Baltimore). 2017;96(28):e7482.

17. Farzianpour F, Kooshad MA. Study of the status of tuberculosis control program based on the implementation of the directly observed treatment short-course strategy (DOTS). Materia socio-medica. 2016;28(4):249.

18. Sandhu GK. Tuberculosis: current situation, challenges and overview of its control programs in India. Journal of Global Infectious Diseases. 2011;3(2):143. 